\title{
As organizações sociais de saúde como forma de gestão público/privado
}

\section{H ealth social organizations as a way of public/private management}

Nelson Bezerra Barbosa ${ }^{1}$

Paulo Eduardo M angeon Elias ${ }^{2}$

\footnotetext{
${ }^{1}$ Secretaria de Estado da SaúdedeGoiás. RuaSC $1 /$ 299, Parque Santa Cruz. 74860-270 Goiânia GO. nelsonbbarbosa@gmail.com ${ }^{2}$ Departamento deM edicina Preventiva, Faculdade de M edicina, Universidade de São Paulo.
}

Abstract This work has as objective to analyze the implementation process of the $\mathrm{H}$ ealth Social Organizations (OSS), in the State of São Paulo, focusing the role played by factors as administrative and financial autonomy, direction proposed by the $M$ anagement Contract and the use of instruments and innovative management practices, as factors that give condition to the gain of efficiency of these OSS facing the Direct Administration units (AD). The adopted approach was the Comparative Study, which proposes the establishment of possibilities, from the confrontation between two units(HOSS and HAD), to identify the elements capable of explaining this difference of performance between the two models of management. The research points to the positive influence of the administrative and financial autonomy, to the direction given to the work processes by goals setting in the $M$ anagement Contract and innovative management technologies with the intensive use of the information as base for taking decisions. This result, far from indicating the complete conversion of $A D$ to the publicizing by the OSS model, points to the possibilities and limits of development of AD, by the incorporation of management technologies in the OSS environment.

Key words Renovation of the health sector, Public-private relation in the health sector, $\mathrm{H}$ ealth social organizations
Resumo 0 presentetem como objetivo analisar o processo de implementação das organizações sociais de saúde (OSS), no Estado deSão Paulo, focalizando o papel desempenhado por fatores como autonomia administrativa e financeira, direcionamento proposto pelo contrato de gestão e o emprego de instrumentos e práticas gerenciais inovadoras, como fatores que condicionam o ganho de eficiência destas (OSS) frente às unidades da administração direta (AD) . A abordagem adotada foi a do estudo comparativo, que propõe estabelecer possibilidades de, a partir da confrontação entre duas unidades (HOSS e H AD), identificar os elementos capazes de explicar esta diferença de desempenho entre os dois modelos de gestão. A investigação aponta para a influência positiva da autonomia administrativa e financeira, da direcionalidade imprimida aos processos de trabalho pelas metas estabelecidas no contrato de gestão e de tecnologias gerenciais inovadoras com uso intensivo da informação como base para a tomada dedecisão. Este resultado, longe deindicar a completa conversão da AD para a publicização por meio do modelo OSS, aponta para as possibilidades e limites de desenvolvimento da AD, pela incorporação de tecnologias gerenciais implementadas no âmbito das OSS.

Palavras-chave Reforma no setor saúde, Relação público-privado no setor saúde, O rganizações sociais de saúde 
Introdução

Ao longo das duas últimas décadas do século passado, assistiu-sea um intenso debate sobrea crise fiscal do Estado, suas implicações sobreo processo de financiamento das políticas públicas e as possíveis al ternativas ao problema. No limite, este debate expressou o enfrentamento entre concepções sobre o papel do Estado e os padrões de intervenção sobre a sociedade. A partir do debate iniciado nos anos noventa no Brasil, quanto à necessidade deuma dada reestruturação do Estado, uma grande quantidade de energia e de produção teórica foi mobilizada em relação ao tema.

N o Brasil, a expressão concreta deste debate está representada no Plano Diretor de Reforma do A parelho do Estado (PDRAE), proposto pelo M inistério da Administração e R eforma do Estado (M ARE) do governo FHC (1995-2002). Não pelo grau de consenso que possa ter al cançado, mas, sobretudo, por referir-se a uma intervenção concreta sobre o problema colocado - as novas relações entre Estado e Sociedade.

$\mathrm{Na}$ área de saúde do governo do Estado de São Paulo, fez-se uma opção por experimentar um novo modelo de gestão para algumas de suas unidades hospitalares, com a implantação de organizações sociais desaúde(OSS), gerenciadas por entidades públicas não-estatais, submetidas a contratos de gestão, que são acompanhados e avaliados por estrutura da Secretaria Estadual de Saúde, criada especificamente para este fim.

De acordo com o PDRAE, Organizações. Sociais (O.S.) são entidades de interesse e de utilidade pública, associação sem fins lucrativos, surgi das da qualificação de pessoas jurídicas de direito privado, nas atividades de ensino, pesquisa tecnológica, desenvolvimento tecnológico, proteção e preservação do meio-ambiente ${ }^{1}$.

Alguns trabal hos realizados sobrea experiência do modelo de gestão organização social de saúde (OSS) apontam para uma vantagem competitiva deste modelo sobre o da administração direta2-5. Esta observação está presente em trabal hos de avaliação realizados pela própria SES$\mathrm{SP}$, quanto em algumas produções acadêmicas. Entretanto, esta constatação não faz referência aos elementos que condicionam os ganhos de eficiência das unidades que funcionam sob o model o OSS, comparativamente às unidades sob o modelo de administração.
Nestesentido, 0 objetivo destetrabalho éidentificar e analisar os fatores que condicionam os ganhos de eficiência das unidades hospitalares sob o modelo OSS, comparativamente às unidades sob administração direta da SES-SP. Tal objetivo expressa a seguinte pergunta de partida: que fatores condicionam o ganho de eficiência das OSS frente às unidades da AD? Para tanto, foram tomados dois hospitais da rede do SUS estadual, inseridos nas duas modalidades de gestão - HOSS e HAD.

O levantamento de dados e informações foi realizado por meio de entrevistas a dirigentes $e$ profissionais das duas unidades investigadas, bem como pela consulta a documentos produzidos no âmbito destas unidades e da SES-SP. As informações levantadas foram as relativas à forma de organização do processo gerencial em cada uma das unidades; a estruturação dos processos de aquisição de bens e serviços; as formas de contratação e administração de pessoal e a organização dos processos de trabal ho de natureza assistencial.

Asinformações levantadas estão referidas pela análise das dimensões selecionadas, seus componentes e indicadores, conforme descrito no Quadro 1. A análise obedeceu às seguintes categorias: autonomia - com foco no binômio centralização/descentralização; práticas gerenciais não usuais em unidades da administração direta - considerando os instrumentos e práticas gerenciais empregados e sua capacidade de influir sobre o desempenho institucional; direcionalidade das ações - observando os indicadores de desempenho em cada unidade e as formas de monitoramento e avaliação empregadas em cada caso.

Os resultados e discussão apontam para o papel da autonomia administrativa e financeira frente ao processo de aquisição de bens e serviços, bem como na contratação de recursos humanos, no melhor desempenho do HOSS frente ao HAD. Indicam, ainda, que o contrato de gestão possibilita, por meio da definição de objetivos e metas a serem alcançados, uma melhor estruturação dos processos de trabalho e a utilização de tecnologias gerenciais inovadoras. Para além de qualquer inferência sobre a ineficiência do setor público, o que o trabalho pretende assinalar é a necessidade de que as inovações propostas por experiências como estas possam ser apropriadas e implementadas, observados dois aspectos centrais - os ganhos de eficiência e a preservação do interesse público. 
Quadro 1. Relação dimensão, componentes e indicadores.

\begin{tabular}{|c|c|c|}
\hline Dimensão & Componentes & Indicadores \\
\hline $\begin{array}{l}\text { Estruturação do } \\
\text { processo gerencial }\end{array}$ & $\begin{array}{l}\text { Estruturas e práticas gerenciais } \\
\text { adotadas. } \\
\text { Enfoque adotado. }\end{array}$ & $\begin{array}{l}\text { Número de estruturas de suporte a processos } \\
\text { gerenciais implantados/contratados } \\
\text { (planejamento, avaliação, informação, custos, } \\
\text { gestão da qualidade, comunicação). }\end{array}$ \\
\hline \multirow[t]{3}{*}{$\begin{array}{l}\text { Recursos humanos/ } \\
\text { política de pessoal }\end{array}$} & $\begin{array}{l}\text { Formas de contratação dos } \\
\text { recursos humanos, segundo } \\
\text { regimes adotados. } \\
\text { Formas de progressão } \\
\text { funcional. }\end{array}$ & $\begin{array}{l}\text { Nível de autonomia para provisão de RH. } \\
\text { Formas de seleção adotadas. } \\
\text { Critérios de progressão funcional existentes. }\end{array}$ \\
\hline & Formas de remuneração. & $\begin{array}{l}\text { Valores de remuneração praticados, } \\
\text { comparados entre si e com os de mercado. }\end{array}$ \\
\hline & $\begin{array}{l}\text { Pessoal disponível em cada } \\
\text { uma das unidades comparadas } \\
\text { erotatividade. }\end{array}$ & $\begin{array}{l}\text { Número de profissionais segundo principais } \\
\text { categorias. } \\
\text { Îndice de rotatividade. }\end{array}$ \\
\hline \multirow[t]{4}{*}{$\begin{array}{l}\text { Organização do } \\
\text { processo de compras }\end{array}$} & $\begin{array}{l}\text { Formas de contratação para } \\
\text { aquisição de bens e serviços. }\end{array}$ & $\begin{array}{l}\text { Modalidades de contratação adotadas. } \\
\text { Nível de descentralização adotado para } \\
\text { aquisiçãa de bens e serviços (\% de itens } \\
\text { comprados de forma centralizada). }\end{array}$ \\
\hline & Fluxo de processos. & $\begin{array}{l}\text { Quantidade de elos presentes na cadeia do } \\
\text { processo (número de estações de operação). }\end{array}$ \\
\hline & $\begin{array}{l}\text { Instrumentos gerenciais } \\
\text { adotados para controle desses } \\
\text { processos. }\end{array}$ & $\begin{array}{l}\text { Nível de informatização no monitoramento } \\
\text { dos processos. }\end{array}$ \\
\hline & $\begin{array}{l}\text { Administração do processo de } \\
\text { guarda e distribuição interna } \\
\text { de bens ou serviços. }\end{array}$ & $\begin{array}{l}\text { Tempo gasto entre pedido e entrega dos bens } \\
\text { ou serviços solicitados. }\end{array}$ \\
\hline \multirow{2}{*}{$\begin{array}{l}\text { Estruturação do } \\
\text { processo de } \\
\text { monitoramento e } \\
\text { avaliação da } \\
\text { atividade } \\
\text { assistencial } \\
\text { (enfermaria de } \\
\text { pediatria) }\end{array}$} & $\begin{array}{l}\text { Quantitativo de pessoal } \\
\text { disponível em cada uma das } \\
\text { unidades de assistência } \\
\text { comparada. }\end{array}$ & Relação profissionais/leito. \\
\hline & $\begin{array}{l}\text { Desempenho dessas unidades. } \\
\text { Controle e avaliação da } \\
\text { produção de procedimentos } \\
\text { assistenciais. }\end{array}$ & $\begin{array}{l}\text { Indicadores de desempenho: } \\
\text { Taxa média de ocupação; tempo médio de } \\
\text { permanência. } \\
\text { Existência de sistemas de sinais } \\
\text { e alarmes adotados para monitoramento de } \\
\text { desempenho. }\end{array}$ \\
\hline
\end{tabular}

\section{A globalização, o redesenho do Estado eos processos de reforma}

Ao longo dos últimos trinta anos, têm sido debatidas e implementadas uma série de medidas que visam adequar o Estado e suas políticas às transformações ocorridas na dinâmica de acumulação capitalista no mundo. A agenda proposta para 0 enfrentamento dessas mudanças tem sido marcada pela emergência de uma nova etapa no processo deinternacionalização da economia, conhecida como globalização, com desdobramentos para outros campos da atividade humana.

Apesar do componente ideológico presente no debate, há evidentes fatores objetivos que demandam a intervenção do Estado para supera- 
ção dos níveis decrescimento econômico enfrentados e sua repercussão sobre o financiamento de políticas públicas. A economia mundial, nos últimos quarenta anos, apresentou taxas de crescimento declinantes. $\mathrm{Na}$ década de sessenta, $\mathrm{O}$ crescimento foi de $5,0 \%$ ao ano (a.a); nos anos setenta, caiu para 3,6\% a.a.; nos anos oitenta, nova desaceleração, com taxa de crescimento de $2,8 \%$ a.a.; na primeira metade da década de noventa, o crescimento registrado foi de $2,0 \%$.

Paral el o a estefato, verifica-se um rápido processo de envelhecimento entre a população dos paísesindustrializados. No começo do século passado, $4 \%$ da população americana tinha mais de 65 anos; em 1997, estegrupo já representava 13\%. Enquanto a relação ativo/inativo é de 4,5/1, em 1997, nos Estados Unidos, para 2030, a projeção é de que esta relação seja de apenas $1,7 / 1^{6}$.

As propostas de reforma vão estar condicionadas por fatores de natureza econômica, na medida em que o diagnóstico aponta para o aumento de custos no setor público ea necessidade de conter o déficit, de natureza política e ideológica, marcada pelo fim da experiência do socialismo real eo consequentefortalecimento da crença no poder do mercado, além de fatores de ordem epidemiológica (prevalência das doenças crônico-degenerativas) e demográfica (aumento da esperança média de vida), com forte impacto sobre as políticas públicas, notadamente na saúdeeprevidência.

A centralidade do Estado como condutor dos projetos de ajuste macroeconômico insere com maior ênfase o debate sobre o tamanho e a função que este deve ter em sua relação com a sociedade. Esta questão coloca em oposição duas grandes concepções: a de corte liberal (Estado mínimo) e a social-democrata (Estado de bemestar social), dentro de um continuum que compreende os seus diversos matizes. Esta polarização se explicita na compreensão sobre as causas da crise fiscal do Estado e suas formas de enfrentamento. 0 projeto neoliberal representa a resposta de governos alinhados com a estratégia de redução do papel do Estado ea tran sferência para o mercado de diversas de suas atribuições e responsabilidades com a oferta e financiamento de bens e serviços públicos ${ }^{7}$.

As duas perspectivas que se colocam, portanto, apontam para: (1) o crescimento do Estado, que transbordou o seu papel e deve, a partir de agora, abster-se de intervir no social e defender que cada indivíduo procure seu bem-estar; (2) a crise é resultante do crescimento do Estado e que o esforço deve ser o de racionalizar e reor- ganizar o Estado e suas políticas sociais, não diminuir o seu tamanho ${ }^{8}$.

A limitada capacidade de financiamento dos gastos públicos, a instabilidade monetária, 0 aumento da inflação, associados a um quadro de profundas transformações nos processos de produção, marcado por forte incorporação tecnológica, abrem a discussão sobre o papel do Estado e sua capacidade de responder aos desafios colocados por essa situação.

0 enfrentamento dessequadro ensejou a proposição de reformas, patrocinadas em grande escala por organismos internacionais, que podem ser classificadas em dois grupos distintos, ou duas gerações de reformas: a primeira relacionada à implementação de medidas de ajustefiscal, privatização e liberalização do comércio; a segunda, pela proposta de reforma do Estado, incluindo a reforma do serviço público ${ }^{9}$.

Ganha força, neste cenário, uma perspectiva de administração gerencial como enfoque a ser adotado para o setor público. Fundamenta-se no desenvolvimento de uma nova economia para este setor, caracterizada por declínio do poder dos sindicatos; enfraquecimento na autonomia dos profissionais dentro do setor público; crescimento deuma elitede dirigentes públicos nomeados; combate às práticas de rent-seeking (refere-se às práticas de apropriação da rês pública por interesses privados, seja pela própria burocracia, através do nepotismo, seja através da ação corruptora de agentes privados. "O rent-seeking équase sempreum modo mais sutil e sofisticado de privatizar o Estado" ${ }^{10}$ ) e novas formas de responsabilidade, com base em uma maior participação da sociedade em atividades antes desenvolvidas pelo Estado (via privatização, descentralização, terceirização, etc.).

0 modelo gerencial, a despeito de sua matização, guarda alguns princípios comuns, como reação ao desperdício, incentivos ao desempenho (com separação entre financiamento e provisão), foco na eficiência. A mudança mais substancial patrocinada pelo surgimento deste novo paradigma está relacionada à formação de paramercados (quase-mercados), com a introdução da contratação e seus desdobramentos sobre o comportamento organizacional ${ }^{11}$.

A ideia central contida na noção de paramercados é a de estimular a introdução de mecanismos de mercado dentro do serviço público, estimulando a competição no seu interior. Os contratos firmados entre compradores e executores (contratos de gestão) se propõem a estimular e premiar a eficiência da organização de serviços 
prestados, dentro da lógica dequeo recurso deve seguir o usuário ${ }^{12}$.

Tal medida se materializa na delegação da execução de atividades a entes públicos não-estatais ou mesmo ao mercado. Propõe, portanto, uma completa redefinição da atividade governamental, cristalizada na visão do governo catalisador/ fomentador. 0 foco da ação governamental estaria em definir as grandes diretrizes para o desenvolvimento social, formular as políticas macroeconômicas, induzir a formação demercados, orientar as prioridades em relação à proteção degrupos vulneráveis e estimular a corresponsabilidade do cidadão na gestão das políticas públicas ${ }^{13}$.

A implementação de reformas foi orientada por alguns princípios e diretrizes que convergem em direção à descentralização e busca de eficiência. No caso do Brasil, a descentralização consistiu na privatização deuma série de atividades econômicas desenvolvidas pelo Estado, pela transferência da execução das políticas públicas a instâncias subnacionais e pela incorporação de entes públicos não-estatais às tarefas de gerenciamento eexecução deações (no queficou conhecido como processo de publicização). Este último aspecto ensejou o surgimento das organizações sociais (OS), objeto de discussão deste trabalho.

\section{Resultadosediscussão}

\section{Autonomia administrativa e financeira}

O nível de autonomia administrativa efinanceira concedido às OSS, tanto para aquisição de bens e serviços quanto para contratação de recursos humanos, permite que, dentro dos limites orçamentários estabelecidos, sejam feitos todos os arranjos institucionais que garantam 0 melhor uso possível dos recursos destinados. A aquisição de bens e serviços está condicionada exclusivamente à observância do preconizado pelo regulamento de compras estabelecido para este tipo de organização.

A simplificação desse processo permite que 0 abastecimento da unidade hospitalar sob esteregimedegestão (OSS) seja feito em intervalos menores e focado nas necessidades de consumo para 0 período, gerando maior rotatividade no estoque com menor ativo imobilizado. Ter processos simplificados, com uma pequena quantidade de estações detrabalho, além da agilidade na execução da tar efa, tende a torná-la menos dispendiosa.

Essa situação encontrada na OSS contrasta com a das unidades da administração direta, sujeitas a um conjunto de controles externos, focados em rituais de procedimentos, que tornam seu processo de aquisição de bens eserviços muito mais lento epouco eficiente. A tendênciaà realização de compras concentradas em grandes intervalos de tempo, ainda que dentro de uma lógica de entrega programada com fornecedores, gera grande quantidade de estoques, com maior ativo imobilizado. A execução de um processo de compras no HAD tem de percorrer dezenove estações de operações até seu fechamento, enquanto no HOSS este processo se resumea três estações (dos setores solicitantes ao setor de compras, deste aos fornecedores selecionados e destes ao almoxarifado).

A possibilidade de organizar fluxos de aquisição de bens e serviços de forma desburocratizada permite a negociação de condições de pagamento e de reposição de material favoráveis à organização. No caso do HOSS investigado, o fato deter sob a sua responsabilidade outras duas unidades hospitalares (uma OSS e outra filantrópica) permite que os processos de compras sejam organizados para abastecimento das três unidades, ampliando o poder de barganha dos compradores.

0 modelo de estruturação do processo de aquisição de bens e serviços implica um maior nível de tensão entre burocratas e profissionais de saúde, em relação sobrea quem compete definir critérios para efetuação do processo. Estetensionamento tem apontado para soluções negociadas, cabendo aos profissionais de saúde a justificação e comprovação da eficácia de materiais e insumos indicados para compra, que devem ser analisadas à luz das disponibilidades orçamentária efinanceira.

A burocratização dos processos de aquisição de bens e serviços tem sido objeto de investimento, seja na perspectiva da criação de novas figuras jurídicas no âmbito da administração pública (autarquias, fundações, empresas públicas, organizações sociais), seja pela tentativa de criar instrumentos mais ágeis e transparentes dentro da legislação adotada para o setor público (pregão eletrônico epresencial). Estes movimentos representam o reconhecimento dos limites impostos pelas regras atuais para garantir abastecimento das unidades do sistema, dentro de limites detempo e qualidade necessários. A busca do ajuste possível entre os tempos técnico e administrativo representa um desafio do sistema na busca da qualificação do seu processo de gestão. 
Gestão das relações de trabalho

e eficiência na $A D$

e nas organizações sociais de saúde

No âmbito dos modelos de gestão adotados no setor saúde em São Paulo (organizações sociais e administração direta), as formas de ordenamento jurídico apresentam desdobramentos em relação aos limites e possibilidades quanto à gestão do trabalho em suas diversas dimensões - recrutamento, seleção, contratação, administração e controle, progressão funcional, entre outras - que impactam sobre a utilização da capacidade instalada de $\mathrm{RH}$.

No âmbito da gerência dos hospitais que operam sob o modelo de administração direta, predominauma situação de baixa autonomia em relação ao controle sobre os $\mathrm{RH}$, que combina limites na capacidade de regulação do sistema, controle de gastos com pessoal decorrente da observância da Lei de Responsabilidade Fiscal e uma gestão centralizada de vários elementos que compõem a política de RH (recrutamento, seleção, incentivos ao desempenho, sanções administrativas).

$N$ as unidades da administração direta (AD), os limites institucionais para implantação e implementação da política de RH estão relacionados ao condicionamento estabelecido por instrumentos que regulam os gastos públicos, que incluem tetos para gastos com pessoal, além de uma legislação que define a forma de ingresso e permanência no serviço público. Predomina nestas organizações a forma de seleção por meio de concurso público, que abrange $80 \%$ dos profissionais da unidade investigada. Esta forma de contratação, entretanto, depende de autorização da área econômica, que observa, além dos limites legais para gasto com pessoal, critérios próprios para alocação de recursos que nem sempre levam em consideração a relevância do setor saúde para o desenvolvimento de um país, estado ou região, mas apenas os gastos envolvidos com a oferta de serviços.

0 processo de alocação de pessoal nos HAD segue parâmetros técnicos baseados na relação profissionais/capacidadeinstalada (profissionais/ leito), definindo os quantitativos que vão compor o quadro de lotação das unidades assistenciais. A lógica tecnocrática não incorpora, entre tanto, a projeção sobre mudanças no perfil de mográfico e epidemiológico das regiões onde estas estão inseridas.

No caso do HAD investigado, o seu quadro de pessoal era o mesmo adotado em sua implan- tação há quinze anos. A criação de novos serviços demandou a necessidade de contratação de profissionais, que por não fazerem parte deste quadro, passaram a ser contratados de forma precarizada (contrato temporário sem nenhum direito trabal hista), situação que abrangia cerca de $20 \%$ dos profissionais desta unidade. Estecenário não apenas contradita o que preconiza a legislação, como coloca, neste caso, a administração direta em situação de desvantagem competitiva frente às organizações sociais.

As limitações quanto ao gerenciamento das relações de trabal ho, no âmbito das unidades da administração direta, são evidenciadas, ainda, nos aspectos relativos ao controle sobre os processos de descontratação, bem como ao da progressão funcional, com implicações sobre os níveis de eficiência destas organizações, considerando a forma burocratizada como estas questões são tratadas.

Em relação ao acesso às vagas, no âmbito do HOSS, o processo sel etivo está orientado por uma segmentação de responsabilidades, quanto à contratação, em três grandes setores: médico, de enfermagem e administrativo. Os dois primeiros responsáveis pela seleção de seus pares, os demais são selecionados pelo setor de administração de pessoal. 0 ingresso é mediante processo seletivo, ancorado, principalmente, em análisede currículo e entrevistas para identificação do perfil do candidato.

Todos os admitidos na organização têm seus vínculos de trabalho ordenados segundo a Consolidação das Leis do Trabalho (CLT), mesmo os contratados por tempo determinado para substituição deférias ou licenças. A definição sobre formas de contratação de pessoal, sob qualquer forma de vínculo, é de decisão exclusiva da OSS, respeitado o limite orçamentário para gasto com pessoal, que é de $70 \%{ }^{14,15}$.

Tendo em vista a inexistência de um plano de cargos, salários e carreira, a perspectiva de progressão funcional é implementada com um forte componente de informalidade, com base na avaliação do desempenho do funcionário realizada pelas chefias imediatas. Os problemas descritos acima têm impacto sobreo desempenho organizacional, influenciando sua capacidade de produção.

Entre os indicadores utilizados para avaliação de produtividade de unidades hospitalares, um dos mais empregados refere-se à relação funcionário/leito. N ão obstante a ten dência à diminuição do número deleitos hospitalares, seja pela transferência de vários procedimentos para a rede 
ambulatorial, pelo estímulo à desospitalização de alguns problemas de saúde (destaque para saúde mental) ou mesmo pela instituição de serviços de homecare, os dados disponíveis sobre este indicador demonstram um aumento desta relação, influenciado pelo processo de incorporação tecnológica observada para o setor saúde.

Trabalho desenvolvido por Zucchi ${ }^{16}$ sobre a situação deste indicador para um conjunto de hospitais públicos e privados no município de São Paulo encontrou uma relação que variou de 5,1 a 13,6. Observando a evolução deste indicador, também para um conjunto de municípios de São Paulo, foi detectado que esta relação passou de 3,2 (1977) para 5,8 (1988), chegando, em 1994, a 7,17.

O Quadro 2 apresenta a situação das unidades hospitalares investigadas, segundo alguns indicadores relativos à eficiência dos serviços. Os indicadores apontam para uma melhor relação funcionário leito, por parte da OSS. As taxas médias de permanência (TMP) apresentam resultados muito próximos para os anos comparados. Este resultado, referente à $T M P$, indica a presença de critérios técnicos compartilhados para conduta em relação àalta, pertinenteao tipo de burocracia que caracteriza organizações hospitalares - as ditas profissionais.
A taxa média de ocupação apresenta convergência em relação aos resultados para 0 ano de 2002. Entretanto, o valor médio para os anos comparados revela uma diferença em favor da OSS (85\%), em relação à unidadeda AD (79,5\%). A meta estabelecida para as OSS, para 0 ano de 2001 , era de uma TM O de $75 \%$, segundo o contrato de gestão $0^{1}$. 0 acompanhamento dos resultados tem permitido a negociação do ajuste das metas entre os contratantes.

Esta diferença no desempenho se expressa em outros dados referentes à produção comparada destas duas unidades, considerando um conjunto de procedimentos, bem como a relação profissional/leito, tomando como base as categorias médica e de enfermagem, conforme o Quadro 3.

Considerando que, para o período acima (2001/2002/2003), as referidas unidades hospitalares apresentavam, segundo relatório de atividades, uma oferta de leitos correspondente a 184/192/202(HAD) e249/264 (HOSS), é possível inferir uma vantagem competitiva da OSS frente ao hospital da administração direta.

Os dados indicam uma melhor utilização da capacidade instalada de RH por parte da OSS; esta melhor relação pode ser explicada pelo limite de gasto em RHS imposto pelo contrato de gestão, aliada à necessidade de al cançar as metas

Quadro 2. H ospitais segundo alguns indicadores de eficiência (2001/2002/2003).

\begin{tabular}{|l|c|c|c|c|c|c|c|c|c|}
\hline \multirow{2}{*}{ Hospitais } & \multicolumn{3}{|c|}{2001} & \multicolumn{3}{c|}{2002} & \multicolumn{3}{c|}{2003} \\
\cline { 2 - 10 } & Func./leito & TM O & TM P & Func./leito & TM O & TM P & Func./leito & TM O & TM P \\
\hline HAD & 7,1 & $81,5 \%$ & 5 & 6,8 & $79,5 \%$ & 5,0 & 6,4 & $77,6 \%$ & 5,1 \\
\hline HOSS & 3,9 & $88,7 \%$ & 4,8 & 3,8 & $80,3 \%$ & 5,05 & 4,1 & $86,1 \%$ & 5,02 \\
\hline
\end{tabular}

Fonte: Relatórios de atividades - H GVP/H GIP.

TM O (taxa média de ocupação) - número de pacientes em determinado período/número deleitos-dia no mesmo período x 100 TM P (taxa média de permanência) - número de pacientes em determinado período/número de pacientes saídos no mesmo período ${ }^{18}$.

Quadro 3. Produção de procedimentos e relação profissional/leito por unidade hospitalar (2001/2002/2003).

\begin{tabular}{|l|l|l|l|l|l|l|l|l|l|l|l|l|}
\hline & \multicolumn{4}{|c|}{ Partos } & \multicolumn{3}{c|}{ Cirurgias } & \multicolumn{3}{c|}{ Enfermeiro/leito } & \multicolumn{3}{c|}{ M édico/leito } \\
\cline { 2 - 13 } Hospitais & 2001 & 2002 & 2003 & 2001 & 2002 & 2003 & 2001 & 2002 & 2003 & 2001 & 2002 & 2003 \\
\hline HAD & 3.221 & 3.297 & 2.593 & 3.306 & 3.177 & 3.476 & 0,29 & 0,29 & 0,32 & 1,54 & 1,53 & 1,46 \\
\hline HOSS & 5.383 & 5.635 & 5.235 & 5.208 & 5.025 & 5.984 & 0,19 & 0,21 & 0,23 & 0,89 & 0,88 & 0,97 \\
\hline
\end{tabular}

Fonte: Relatório deAtividades - HAD / HOSS. 
estabelecidas neste contrato, dentro dos limites orçamentários definidos. As discretas tendências de aumento nesta proporção (funcionário/leito) na OSS ediminuição naAD estão referidasà crescente ampliação da oferta de serviços desde a abertura da unidade (1998), em relação à primeira, e à dificuldade para contratação de pessoal para suprir necessidades (inclusive de expansão de serviços), no caso da segunda.

Rotatividades e remuneração

nas experiências da AD e OSS

A adoção de mecanismos de mercado para contratação de pessoal pode assegurar um processo de reposição de necessidades mais ágil e mais aderido às necessidades da população usuária dos serviços, com possibilidades de melhor utilização da capacidade instalada física e de RH . Entretanto, 0 apelo ao mercado tende à conformação de uma maior instabilidade no quadro funcional, caracterizada por altos índices de rotatividade, contrariando a expectativa de quecontratação com salários acima da média paga pela administração direta (dado que não se confirma para todas as categorias) venha a ser fator de manutenção de contratados em áreas distantes.

Índice de rotatividade: mede a relação entre entrada e saídas de funcionários, segundo o período avaliado. Expresso sob a forma de percentual, com base no cálculo: média entre admissões e demissões, dividida pela média de funcionários em um determinado período, multiplicado por $100^{19}$.

A alta rotatividade de pessoal, no caso da OS estudada, pode ser atribuída à localização desta e aos problemas decorrentes deacesso a outros pontos da cidade, que devem influenciar no exercício demúltiplos vínculos detrabalho comuns entreas duas categorias representadas no Quadro 4. Esta avaliação deve ser comparada com a situação de

Quadro 4. Índice de rotatividade por categoria e hospital (2002/2003, período de janeiro a julho)

\begin{tabular}{|l|c|c|c|c|}
\hline \multirow{2}{*}{ Categoria } & \multicolumn{2}{|c|}{ HAD } & \multicolumn{2}{c|}{ HOSS } \\
\cline { 2 - 5 } M édico & 2002 & 2003 & 2002 & 2003 \\
\hline Enfermagem & $1,2 \%$ & $0,6 \%$ & $19,22 \%$ & $12,18 \%$ \\
\hline Geral & $2,0 \%$ & $5,9 \%$ & $16,8 \%$ & $11,09 \%$ \\
\hline
\end{tabular}

Fonte: Coordenação deRH - HAD/HOSS. outras OSS localizadas em pontos mais centrais da cidade para que possa ser corroborada.

Em relação à unidade da administração direta, épreciso considerar que as condições deacesso ao cargo, que na maioria dos casos se faz mediante concurso público, aliadas à maior flexibilidade no exercício das atividades, deve influir na sua baixa rotatividade, comparativamente à OS. Um estudo mais detalhado sobre os motivos de recusa à participação em concursos públicos por certas especialidades, bem como sobreos motivos de pedidos de exoneração, pode informar mais sobre as razões desta baixa rotatividadenaAD.

$O$ efeito deum al to índice derotatividadeestá relacionado ao risco de solução de continuidade no desenvolvimento das atividades, à sobrecarga de trabalho aos que se mantêm na unidade até a substituição e adaptação funcional dos novos contratados, ou mesmo quanto as suas repercussões sobre projetos de desenvolvimento institucional, que dependam da expertise dos egressos da organização.

Uma das premissas para construção do SUS era a de que a unificação do sistema implicaria tratamento igualitário aos trabalhadores do setor público, independente do nível de gestão a que estivessem vinculados. A pontava para o processo de estruturação de planos de cargos e carreira como estratégia privilegiada. A descentralização de recursos e atribuições entre os gestores do sistema dificultou o desenvolvimento desta estratégia. Não apenas foi impossível até o momento promover isonomia salarial no setor, como a adoção de novos arranjos institucionais na relação público versus privado instituiu outras modalidades de contratação de pessoal com diferentes formas e valores de remuneração. $\mathrm{Na}$ $A D$, prevalece admissão por concurso público, regido por estatutos.

Os níveis de remuneração praticados na $A D$ são considerados como defasados, quando comparados àqueles praticados no setor privado, considerando a remuneração da categoria médica como base de comparação.

O salário-base pago pela Secretaria de Estado de São Paulo, em 2001, para vinte horas semanais, era de $R \$ 1.253,00$. Esses valores estão aquém da média de salário do Estado ( $R \$$ $2.585,79)$ e da recomendação da Confederação $\mathrm{N}$ acional dos M édicos $(\mathrm{R} \$ 2.500,00)^{20}$.

As médias salariais praticadas pelas duas unidades públicas (OSS e AD) são inferiores àquelas praticadas pelo mercado entre a categoria médica, com uma diferença em torno de 7,9\% frenteà 


\begin{tabular}{l}
\hline Quadro 5. M édias salariais por categoria e hospital (2003). \\
\begin{tabular}{|l|c|c|c|}
\hline \multicolumn{1}{|c|}{ Categoria } & HAD* & HOSF* & M ercado** \\
\hline M édico & $\mathrm{R} \$ 2.393,16(100 \mathrm{~h})$ & $\mathrm{R} \$ 2.909,47(120 \mathrm{~h})$ & $\mathrm{R} \$ 3.156,00(120 \mathrm{~h})$ \\
& $(91 \%)$ & $(92,1 \%)$ & $(100 \%)$ \\
\hline Enfermeira & $\mathrm{R} \$ 1.655,12(150 \mathrm{~h})$ & $\mathrm{R} \$ 2.835,69(180 \mathrm{~h})$ & $\mathrm{R} \$ 2.702,00(180 \mathrm{~h})$ \\
& $(73,5 \%)$ & $(104.9 \%)$ & $(100 \%)$ \\
\hline Auxiliar de enfermagem & $\mathrm{R} \$ 1.056,09(150 \mathrm{~h})$ & $\mathrm{R} \$ 1.403,35(180 \mathrm{~h})$ & $\mathrm{R} \$ 1.311,00(180 \mathrm{~h})$ \\
& $(96,7 \%)$ & $(107 \%)$ & $(100 \%)$ \\
\hline
\end{tabular}
\end{tabular}

Fontes: * Coordenação deRH - HOSS/H AD; ** SES-SP/Coordenação deContrato deServiços de Saúde (CCSS)/D epartamento de Gestão e Controle de Contratos (DGCC).

OS e de aproximadamente $9 \%$ em relação à unidade da administração direta. Em relação às enfermeiras, a diferença, comparativamente aos valores praticados pelo mercado, apresenta uma vantagem de $4,9 \%$ em favor da OS, e uma defasagem de $26,5 \%$ em relação à unidade da AD. Em relação às auxiliares de enfermagem, a diferença entre os valores de mercado e OS chega a $7 \%$ em favor da OS e apresenta uma pequena defasagem de 3,3\% frente à unidade da administração direta (Q audro 5).

Essa comparação, quando realizada entre a unidade no modelo OS e da administração direta, apresenta a seguintesituação: em relação à categoria médica, há uma diferença em favor da unidade da OS em torno de 1,4\%\%; esta situação se mantém em relação às enfermeiras, com umadiferença de 30\% em favor da OS; entre as auxiliares de enfermagem, a vantagem da OS frente a unidade da AD éde $9,7 \%$. A comparação feita entrea unidade sob gestão direta com a OS e os valores de mercado levou em consideração a carga horária contratual entre a primeira e as demais.

Importante ressaltar o fato de que os valores praticados pela unidade sob gestão direta são inferiores aos valores de mercado. Este fato caracteriza a desval orização dos RH eestá no centro do constante processo de migração da mão de obra com melhor nível de qualificação em direção ao mercado. A pesar da autonomia concedida às OSS, ainexistência deuma política de $\mathrm{RH}$, queincluaa perspectiva de progressão funcional para todas as categorias, bem como remuneração mais próxima aos valores de mercado para a categoria médica, poderá estar influindo sobre os índices de rotatividade observados nesta unidade.

Tomando como referência a remuneração média praticada pelo mercado, pode ser obser- vada uma discrepância entre a remuneração oferecida pelo setor público eo nível de qual ificação das categorias profissionais comparadas. A distribuição dos valores praticados pela $A D$, segundo nível de aproximação com o mercado, apresenta a seguinte ordem: auxiliares de enfermagem, médicos e enfermeiras. Em relação à OSS, é possível observar a seguinte ordem de importância: auxiliares de enfermagem, enfermeiras e médicos. N este caso (da OSS), há uma clara opção por um investimento maior junto aos profissionais envolvidos com a prestação do cuidado direto e continuado ao usuário.

As dificuldades para enfrentar o problema do ordenamento das relações de trabalho, em especial quanto aos níveis de remuneração, abrem espaço para adoção de medidas que objetivam compensar defasagens entre valores praticados entre o setor público e o mercado, como a instituições degratificação de diversos tipos (por assiduidade, produtividade, locomoção até o local de trabalho), que devem ser subtraídas do cálculo do benefício da aposentadoria.

A SES-SP instituiu, no âmbito das unidades daAD, a incorporação de uma gratificação, como forma de incentivo ao desempenho, que na prática funciona como complementação salarial, na medida em que não foram estabelecidos mecanismos einstrumentos de avaliação de desempenho individual ou setorial que servissem de parâmetros para o pagamento desta gratificação, ou seja, não estão vinculados a critérios de eficiência a serem atingidos.

A instituição denovos arranjos institucionais na relação público versus privado no setor saúde, em especial da figura jurídica emergente nesta relação - as organizações sociais de saúde - coloca para o SUS o desafio de criar formas de or- 
denamento das relações de trabalho que comportem a diversi dade de formas de seleção, contratação, vínculo e remuneração que esta modalidade de gestão agrega às já existentes, que afasta, cada vez mais, a aplicação de mecanismos de isonomia entre os profissionais do setor.

Contrato de gestão

e direcionalidade do trabalho

Dentro do processo de contratualização das OS, o papel do contrato de gestão é o de estabelecer objetivos, metas e indicadores que deverão ser observados na avaliação de desempenho destas organizações, além de estabelecer responsabilidades do contratante quanto a compromissos assumidos frente à transferência de recursos financeiros e à cooperação técnica necessários à consecução dos resultados esperados.

A definição de metas e indicadores informa a direcionalidade dos processos de trabalho a serem implementados dentro da organização. A desagregação de metas da unidade entre os seus diversos setores eentre os $\mathrm{RH}$ quecompõem cada setor indica os resultados a serem buscados entre estes (setores e profissionais). Essas metas e indicadores são pactuados entre contratante e contratado com base na avaliação da capacidade instalada das unidades e da série histórica sobre a produção destes hospitais.

A existência de um sistema de metas permite uma melhor avaliação do desempenho setorial e pessoal de RH da unidade hospitalar, além de indicar os critérios de eficiência com a qual esta opera. Os níveis de eficiência e eficácia alcançados constituem-se em aspectos fundamentais da capacidadegerencial da rededecomando dequalquer organização. No caso das OSS, o cumprimento das metas estabelecidas no contrato de gestão configura cláusula contratual que condiciona a sua manutenção (do contrato).

Os contratos de gestão constituem-se em instrumento fundamental para o disciplinamento da relação público-privado, como também entre entes públicos, como no caso da relação entre as agências e os órgãos aos quais estas se vinculam. O contrato, ao definir os objetivos e metas a serem al cançados pelo contratado e as condições a serem observadas pela parte contratante, estabelece a direcionalidade dos processos de trabalho para as partes envolvidas na contratual ização.

0 problema que esta condição para a permanência dos vínculos contratuais pode gerar é o deinstitucionalização do sistema demetas como objetivo autorreferido, desvinculando o alcance de resultados do impacto sobre indicadores de saúde da população da área de abrangência da unidade hospitalar.

No caso das OSS, o cumprimento do acordado é condição para manutenção do vínculo contratual; neste sentido, a observância do pacto firmado orienta todo esforço de organização do processo gerencial, incidindo sobre a capacidade produtiva destas unidades. Considerando a existência deiniciativas por partedaSES-SP na implementação deste instrumento, como forma de estruturar a gestão das unidades sob administração direta, é possível afirmar que o contrato de gestão incide positivamente sobre o melhor desempenho das OSS frente às unidades sob regime de AD.

$O$ alcance deum instrumento como o contrato de gestão, seja como ferramenta indutora de busca de eficiência do sistema ou como instrumento de regulação entreo setor público eo privado, vem sendo explorado no âmbito da gestão estadual do SUS por meio de sua expansão para unidades sob regime de administração direta. 0 Projeto de Modernização da Gestão Hospitalar da SES-SP apoia-se na experiência desenvolvida com a introdução destemecanismo de contratualização e propõe a sua aplicação a estas unidades.

Sob a denominação de "termo de compromisso" (TC), vem sendo implantado, em um grupo deunidades, um processo denegociação quanto à definição de um elenco de metas a serem alcançadas. 0 desenho geral deste processo tomou como referência a forma como foram acordados eimplantados os contratos de gestão com as OSS. Implica, portanto, compromissos com investimento na melhoria da infraestrutura destas unidades e na capacitação de RH para apropriação de novas tecnologias gerenciais, como condição para otimizar a relação recurso-desempenho.

Instrumentos

e práticas gerenciais inovadoras

A implementação de instrumentos e práticas gerenciais está referida ao uso de tecnologias aplicadas à organização, controle e avaliação das atividades desenvolvidas, considerando a sua relação com objetivos definidos. Esse processo implica capacidade para otimizar o uso de recursos disponíveis na organização e de articular negociação interna, visando consensos possíveis frente aos diversos interesses existentes.

A cúpula estratégica tem a atribuição degerir o plano de trabalho da unidade, considerando os objetivos e metas pactuados entre direção da unidade e o nível central da SES e incorporados 
ao contrato de gestão, no caso da OSS, ou por deliberação do colegiado de gerência, no caso da unidade da administração direta. Em ambos os casos, a definição de metas tem adotado, prevalentemente, a avaliação da série histórica da produção de procedimentos eda evolução deindicadores de utilização e de qualidade dos serviços.

De maneira geral, o processo gerencial, nas duas unidades, está suportado em estruturas e práticas detrabalho que orientam o processo decisório. Os setores identificados como estratégicos para este fim são os sistemas de informação, os sistemas de custos e de ouvidoria, além dos próprios colegiados de gerência. Ossistemas deinformação cumprem o papel desinalizar quais as áreas críticas quanto às metas estabelecidas, apontam que indicadores precisam ser melhorados. Ossistemas de custos identificam o nível de eficiência, considerando a relação entre os gastos efetuados por setor e o número de procedimentos realizados. 0 sistema de ouvidoria tem a função deidentificar o nível de satisfação/insatisfação do usuário com a qualidade do serviço prestado.

Há uma grande convergência quanto à utilização destes sistemas nas duas unidades hospitalares. 0 monitoramento de indicadores de utilização da capacidade instalada é realizado por um sistema integrado, que pode ser acessado de vários pontos das duas unidades. Esse sistema informa, ainda, sobre níveis de estoque de material e insumos cada vez que uma solicitação de suprimento de al gum setor é feita.

Os sistemas de custos implantados nos dois hospitais também são estruturados sob a mesma metodologia, de custeio por absorção. Em relação às OSS, a implantação e desenvolvimento do sistema foram realizados por empresa contratada pela SES-SP, com o objetivo de homogeneizar os sistemas aplicados a estas unidades e poder estabelecer, a partir desse princípio, condições de comparabilidade entre as unidades sob essa forma de gestão. Na unidade da $A D$, o sistema foi desenvolvido por técnicos da organização e objetiva atender necessidade da gerência de instituir formas de controle sobre os gastos efetuados, independentemente de quaisquer demandas externas. Ossistemasutilizadosnas duas unidades (OSS eAD) operam sob a mesma lógica metodológica.

As diferenças em relação aos modelos de gestão em queas duas unidades seencontram inseridas não se traduzem na adoção de instrumentos e práticas gerenciais inovadoras, dentro da abordagem ao conceito de inovação definido no escopo deste trabal ho eque está relacionado a instrumentos e práticas gerenciais de baixa utilização no setor público, que permita uma significativa distinção entreosmétodos degerenciamento aplicados a cada uma das unidades investigadas.

\section{Consideraçõesfinais}

O objetivo a que se propôs o presente trabalho foi o de identificar eanal isar os aspectos que condicionam os ganhos de eficiência das unidades hospital ares sob o modelo OSS, comparativamente às unidades sob administração direta da SESSP, objetivo expresso na pergunta de partida.

A discussão sobre a relação entre as informações levantadas e a hipótese do trabal ho sugere que: a autonomia administrativa efinanceira para provisão de bens e serviços e administração de pessoal interfere sobre o desempenho das duas unidades, com vantagem para a OSS. A capacidade de decidir sobre a organização da infraestrutura dos serviços e estruturá-la segundo critérios de eficiência e eficácia de forma desburocratizada permite uma melhor alocação de tempo e atenção a uma agenda de prioridades.

Um maior nível de autonomia concedida às unidades sob gestão OSS implica uma maior capacidade de controle e avaliação por parte do gestor estadual em relação aos resultados contratados, bem como um maior domínio dos órgãos de controle externo de novos conceitos e ferramentas focados no desempenho destas unidades, em detrimento do prevalente controle sobre procedimentos.

A integração entre recursos emetas permitea estruturação dos processos de trabalho informados por uma direcionalidade focada na busca da eficiência. 0 papel desempenhado pelos contratos de gestão, para além de estabelecer controle sobre o desempenho das unidades contratadas, serve como parâmetro para definição da alocação interna de recursos e dos custos envolvidos nos procedimentos e serviços produzidos.

Para o contratante (SES-SP), além de um espaço para testagem e validação de novas tecnologias gerenciais e de atenção, tem possibilitado o aperfeiçoamento do processo degestão: as mudanças propostas no desenho do contrato degestão são um exemplo deste esforço. A implantação dos termos de compromisso junto a algumas unidades da AD, baseados na lógica dos contratos de gestão, refere um esforço institucional de apropriação dos resultados col hidos na experiência com as OSS.

Os resultados encontrados neste trabalho, diferentemente do que poderia supor, não refe- 
rendam uma imagem do público como expressão de ineficiência administrativa, mas sublinham al guns el ementos condicionantes em seu desempenho, ancorados em regras incompatíveis com a velocidade das respostas que este (o setor público) deve promover, tendo em vista as demandas e necessidades da população. 0 descompasso entre os tempos técnico e administrativo em um setor como saúde tem repercussões importantes sobre a capacidade do setor em operar mudanças nos indicadores de morbidade e mortalidade da população.

A complexa arquitetura do Sistema Ú nico de Saúde ea dificuldade deimplementação em contextos tão diversos em um país como o nosso impõem a necessidade de que sejam experimentados novos modelos de gestão de ações e servi- ços, capazes de gerar aprendizagem organizacional necessária ao desenvolvimento do sistema. Os resultados indicam a existência de um esforço institucional organizado na SES-SP, destinado ao aprimoramento dos mecanismos empregados na administração direta.

As possibilidades e limites destas experiências de inovação gerencial devem ser capazes de indicar os elementos centrais que devem compor os projetos de reestruturação da administração pública. Os resultados destas experiências e a possibilidade de sua incorporação ao processo de gestão pública podem ser determinantes para o desenho de uma nova forma de organização administrativa para o setor, que seja eficiente, efetiva e voltada para a preservação do interesse público.

\section{Colaboradores}

N B Barbosa ePEM Elias participaram igualmente de todas as etapas da elaboração do artigo. 


\section{Referências}

1. I bañez N, Bittar OJNV, Sá EN C, Yamamoto EK, Almeida MF, Castro CGJ. Organizações sociais de saúde: 0 modelo do Estado de São Paulo. Cien Saude Colet 2001; 6(2):391-404.

2. Carneiro Jr. N. 0 setor público não-estatal: as organizações sociais como possibilidades e limites na gestão pública da saúde [tese]. São Paulo (SP): Faculdade de Medicina, Universidade de São Paulo; 2002.

3. Seixas PHD. As organizações sociais de saúde em São Paulo: 1998 - 2002 [dissertação]. São Paulo (SP): Fundação Getúlio Vargas; 2003.

4. Ferreira Júnior WC. Gerenciamento de hospitais estaduais paulistas por meio das organizações sociais de saúde. Rev. Adm. Pública 2003; 37(2):243-264.

5. São Paulo. Secretaria de Estado da Saúde. A contratação de serviços de saúde como estratégia de gestão pública. São Paulo: Secretaria de Estado da Saúde; 2002.

6. Thurow LC. 0 futuro do capitalismo. $2^{2}$ ed. Rio de Janeiro: Rocco; 1997.

7. Laurell AC. Avançando em direção ao passado: a política social do neoliberalismo. In: Laurell AC, organizadora. Estado e políticas sociais no neoliberalismo. 3a ed. São Paulo: Cortez; 2002. p. 151-178.

8. Gerschman S. Las reformas del Estado, de las políticas sociales y de salud. Un balance del final del milenio. Cad Saude Publica 1999; 15(2):293-302.

9. Bresser Pereira LC. Reforma da nova gestão pública: agora na agenda da América Latina, no entanto... Revista do Serviço Público 2002; 53(1):5-27.

10. Bresser Pereira LC. Gestão do setor público: estratégia e estrutura para um novo Estado. In: Bresser Pereira LC, Spink P, organizadores. Reforma do Estado e Administração Pública Gerencial. 4aㅡ ed. Rio de Janeiro: FGV; 2001. p. 21-38.

11. Ferlie E, Asburner L, Fitzgerald L, Pettigrew A. A nova administração pública em ação. Brasília: UNB/ ENAP; 1999.

12. Trosa S. Gestão pública por resultados: quando o Estado se compromete. Brasília: ENAP; 2001.
13. Osborne D, Gaeble RT. Reinventando o governo como 0 espírito empreendedor está transformando 0 setor público. 10ª ed. Goiânia: M H Comunicação; 1998.

14. São Paulo. Projeto de Lei Complementar $n=3$, de 17 de fevereiro de 1998. Dispõe sobre a qualificação de organizações sociais. Diário Oficial do Estado de São Paulo 1998; 19 fev.

15. São Paulo. Lei Complementar $n^{\circ} 846$, de 4 de junho de 1998. Dispõe sobre a qualificação de entidades como organizações sociais. In: Lex: coletânea de legislação e jurisprudência. Vol. 62. São Paulo: Lex Editora; 1998. p. 906-913.

16. Zucchi P. Funcionários por leito: estudo em alguns hospitais públicos e privados. Rev. Adm. Pública 1998; 32(3):65-76.

17. Bittar OJNV. Produtividade em hospitais de acordo com alguns indicadores hospitalares. Rev. Saude Publica 1996; 30(1):53-60.

18. Bittar OJNV. Distribuição de Recursos Humanos em oito hospitais gerais de São Paulo. Rev. Panam. Salud Públ. 1997; 2(31):37-43.

19. Unisinos. Sistema de Indicadores Padronizados para Gestão Hospitalar - SIPAGEH. [acessado 2004 ago]. Disponível em: http://www.economicas.unisinos.br/ sipageh/apres.php

20. Pierantoni $C R$. Recursos humanos e gerência no SUS. In: Viana ALd'A, Negri B, organizadores. 0 Sistema Ú nico de Saúde em dez anos de desafio. São Paulo: Sobravime/Cealag; 2002. p. 609-630.

Artigo apresentado em 25/10/2007

Aprovado em 04/06/2008

Versão final apresentada em 21/07/2008 